\title{
Ambulatory Toxicity Management (AToM) Pilot: results of a pilot study of a pro-active, telephone-based intervention to improve toxicity management during chemotherapy for breast cancer
}

Monika K. Krzyzanowska ${ }^{1,2^{*}}$, Cassandra MacKay ${ }^{1}$, Heekyung Han ${ }^{1}$, Maria Eberg ${ }^{1}$, Sonal Gandhi ${ }^{3}$, Nicole B. Laferriere ${ }^{4}$, Melanie Powis ${ }^{2}$, Doris Howell ${ }^{2}$, Clare L. Atzema ${ }^{3}$, Kelvin K. W. Chann ${ }^{3,5}$, Vishal Kukreti ${ }^{2}$, Sandra Mitchell ${ }^{6}$, Marla Nayer ${ }^{7}$, Mark Pasetka ${ }^{3}$, Dafna Knittel-Keren ${ }^{2}$ and Erin Redwood ${ }^{1}$

\begin{abstract}
Background: Chemotherapy is associated with a significant risk of toxicity, which often peaks between ambulatory visits to the cancer centre. Remote symptom management support is a tool to optimize self-management and healthcare utilization, including emergency department visits and hospitalizations $(E D+H)$ during chemotherapy. We performed a single-arm pilot study to evaluate the feasibility, acceptability, and potential impact of a telephone symptom management intervention on healthcare utilization during chemotherapy for early stage breast cancer (EBC).

Methods: Women starting adjuvant or neoadjuvant chemotherapy for EBC at two cancer centres in Ontario, Canada, received standardized, nurse-led calls to assess common toxicities at two time points following each chemotherapy administration. Feasibility outcomes included patient enrollment, retention, RN adherence to delivering calls per the study schedule, and resource use associated with calls; acceptability was evaluated based on patient and provider feedback. Impact on acute care utilization was evaluated post hoc by linking individual patient records to provincial data holdings to examine ED+H patterns among participating patients compared to contemporaneous controls.

Results: Between September 2013 and December 2014, 77 women were enrolled (mean age 55 years). Most commonly used regimens were AC-paclitaxel (58\%) and FEC-docetaxel (16\%); 78\% of patients received primary granulocyte colony-stimulating factor prophylaxis. $83.8 \%$ of calls were delivered per schedule; mean call duration was $9 \mathrm{~min}$. The intervention was well received by both patients and clinicians. Comparison of ED+H rates among study participants versus controls showed that there were fewer ED visits in intervention patients [incidence rate ratio (IRR) $(95 \% \mathrm{Cl})=0.54(0.36,0.81)]$ but no difference in the rate of hospitalizations [IRR $(95 \% \mathrm{Cl})=1.02(0.59,1.77)]$. Main implementation challenges included identifying eligible patients, fitting the calls into existing clinical responsibilities, and effective communication to the patient's clinical team.

(Continued on next page)
\end{abstract}

\footnotetext{
* Correspondence: monika.krzyzanowska@uhn.ca

${ }^{1}$ Cancer Care Ontario, Toronto, ON, Canada

University Health Network, Toronto, ON, Canada

Full list of author information is available at the end of the article
}

(c) The Author(s). 2019 Open Access This article is distributed under the terms of the Creative Commons Attribution 4.0 International License (http://creativecommons.org/licenses/by/4.0/), which permits unrestricted use, distribution, and reproduction in any medium, provided you give appropriate credit to the original author(s) and the source, provide a link to the Creative Commons license, and indicate if changes were made. The Creative Commons Public Domain Dedication waiver (http://creativecommons.org/publicdomain/zero/1.0/) applies to the data made available in this article, unless otherwise stated. 
(Continued from previous page)

Conclusions: Telephone-based pro-active toxicity management during chemotherapy is feasible, perceived as valuable by clinicians and patients, and may be associated with lower rates of acute care use. However, attention must be paid to workflow issues for scalability. Larger scale evaluation of this approach is in progress.

Keywords: Breast cancer, Symptom management, Chemotherapy toxicity, Telephone case management, Quality improvement

\section{Background}

Systemic therapy can improve the outcomes of patients with cancer, but carries a substantial risk of toxicity, which often peaks between visits to the cancer clinic. Suboptimal management of toxicities can lead to emergency department visits and hospitalizations $(\mathrm{ED}+\mathrm{H})$ during treatment. The growing number of studies reporting high rates of acute care utilization during chemotherapy across countries and settings $[1,2]$ suggests that our current models for managing toxicities among patients receiving chemotherapy in ambulatory settings may be inadequate. By providing patients with self-management strategies or alternatives to the emergency department for further assessment, early intervention can help to address toxicities before they become too severe $[3,4]$.

Pro-active management of symptoms has been shown to decrease acute care use in chronic diseases such as congestive heart failure [5]. In oncology specifically, studies suggest that remote, often telephone-based, nurse-led symptom-focused interventions are feasible, may improve symptom control and decrease unscheduled emergency room visits and hospitalizations [6-11]. A recently published, single-centre randomized controlled trial of remote web-based patient-reported symptom assessments coupled with automatic provider alerts $[12,13]$ demonstrated that patients receiving remote monitoring had fewer emergency department visits ( $34 \%$ vs $41 \%$ ) or hospitalizations ( $45 \%$ vs $49 \%$ ), remained on chemotherapy longer (8.2 vs 6.3 months), and had better survival relative to patients receiving usual follow-up care. All of these studies, however, have evaluated the impact of these types of interventions in the research setting and have not addressed the additional barriers associated with the implementation and sustainability in routine ambulatory cancer care. As such, further evaluation is needed to inform effective integration of pro-active toxicity management into existing models of care.

The purpose of this single-arm pilot study was to assess the feasibility and acceptability of implementing a nurse-led, pro-active, telephone-based toxicity management into routine clinical practice for patients receiving chemotherapy for early-stage breast cancer and to evaluate potential impact on emergency room visits and hospitalizations during treatment. The goal was to inform larger scale implementation and evaluation. We chose to focus on women with breast cancer as previous population-based studies have reported high rates of treatment-related toxicities and acute care utilization during treatment in this patient population [14-16]. In addition, confounding from symptoms related to advanced cancer is likely to be small in this population given the early stage of disease.

\section{Methods \\ Study design and participants}

To evaluate the feasibility and acceptability of implementing a pro-active, telephone-based toxicity management intervention, we undertook a single-arm prospective pilot study in two academic institutions with integrated cancer programs, in Ontario, Canada, that responded to a request to participate. Women newly diagnosed with early-stage breast cancer (stages I-III) who were initiating adjuvant or neoadjuvant chemotherapy, had an adequate command of English to complete questionnaires, and provided individual consent to participate were eligible. Patients receiving treatment with an investigational agent were excluded because the focus of the intervention was on patients treated in routine care. To understand the feasibility of using administrative data to look at acute care utilization during treatment and evaluate the potential impact of the intervention on acute care utilization, an administrative data-based analysis was also undertaken. A contemporaneous control cohort was identified after the study completion from the Activity Level Report (ALR) database, which was linked to other administrative databases to capture information on patient demographic and clinical characteristics, and outcomes. The control cohort consisted of all other patients diagnosed with early-stage breast cancer who were initiating the same chemotherapy regimens as study participants in the two participating institutions during the study intervention period but who did not participate in the prospective pilot (Additional file 1: Figure S1).

\section{Description of the intervention}

Educational handouts discussing treatments and management of toxicities dispensed to patients initiating treatment differ by provider and cancer centre. As such, all patients were provided with a standardized symptom self-management guide prior to initiating chemotherapy 
which included recommendations for self-management of common toxicities. The content of the guide was adapted from information available on the Canadian Cancer Society and American Cancer Society web pages. The guide covered a subset of 9 toxicities from the National Cancer Institute's Patient-Reported Outcomes version of the Common Terminology Criteria for Adverse Events (NCI PRO-CTCAE). These were chosen from the 124-item bank through expert consensus (by the project steering committee) to reflect commonly experienced toxicities by breast cancer patients who are treated with chemotherapy that may lead to $\mathrm{ED}+\mathrm{H}$ and are amenable to early intervention $[17,18]$. The subset of toxicities included the following: nausea, vomiting, mouth and throat sores, pain, aching joints and muscles, loose and watery stools, shivering or shaking chills, constipation, and fatigue.
The intervention consisted of two pro-active telephone calls following each chemotherapy administration: at 24 to $72 \mathrm{~h}$ and at 8 to 10 days post-chemotherapy (Fig. 1). The calls were made by nurses located at the patient's treating institution. Participating nurses received training on the study protocol and intervention during a study kick-off meeting and participated in monthly study calls to troubleshoot logistics of delivering the intervention. Toxicity assessments, management recommendations, and documentation were standardized using a form covering the same nine toxicities as the patient symptom self-management guide and a companion provider symptom management guide, consistent with best practices and current evidence. Local implementation logistics regarding delivery of the intervention and data collection were determined by the participating centres.

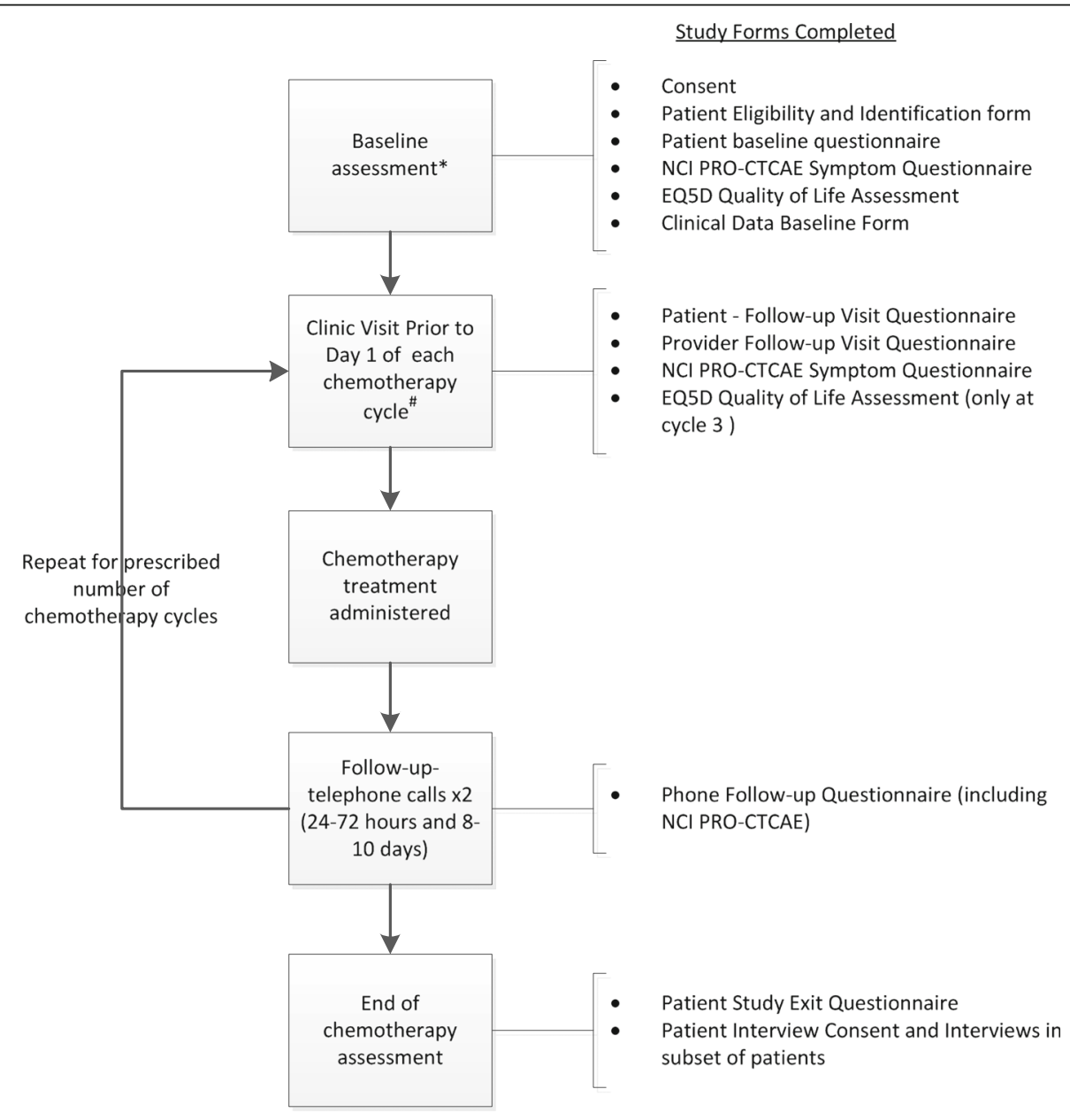

* Completed prior to the first cycle of chemotherapy

${ }^{*}$ Completed at Cycle 2 clinic visit and onwards

Fig. 1 Schedule of study activities and assessments 


\section{Analysis of feasibility and acceptability}

The primary focus of the evaluation was on the feasibility and acceptability of implementation, for which a target recruitment of up to 100 women was considered sufficient based on the literature $[19,20]$. A formal sample size calculation was not undertaken. Feasibility was assessed based on patient enrollment, retention, $\mathrm{RN}$ adherence to delivering calls per the study schedule, and resource use (non-pharmacological or pharmacological recommendations, healthcare provider visit or urgent care). Acceptability of the intervention was assessed from the perspectives of patients and providers using end-of-study surveys (patients) and semi-structured interviews (patients and providers). Following the completion of the last cycle of chemotherapy and related calls, all patients were invited to complete an end-of-study survey that sought feedback on the patient symptom self-management guide and the follow-up calls. Feasibility and acceptability findings are reported as a proportion; 95\% confidence intervals (95\% CI) were calculated to represent variance in the observed proportion. A convenience sample of 17 patients also participated in the end-of-study semi-structured telephone interviews on the patients' experiences with the intervention. In addition, interviews were conducted with providers involved in delivering the intervention to evaluate the barriers and facilitators of implementation and recommendations for improving intervention delivery. Qualitative data from the interviews was analysed using inductive content analysis to derive themes and sub-themes that were grounded in the experience of patients and clinicians [21]. Whether or not the intervention was considered acceptable and feasible was determined by the project steering committee based on the review of the experience with recruitment, delivery of intervention, and feedback from patients and providers following completion of the study.

\section{Analysis of acute care utilization}

An administrative data-based analysis was undertaken to assess the feasibility of using administrative data to look at $\mathrm{ED}+\mathrm{H}$, to evaluate sample representativeness, and to compare the rates of acute care visits among pilot study participants against patients receiving care at the participating centres during the same time frame but who did not participate in the pilot (contemporaneous controls). Pilot study participants were identified deterministically in the provincial data holdings. Information on chemotherapy regimen was obtained from the Activity Level Reporting (ALR) database. Information on ED visits and hospitalizations from initiation of chemotherapy until 30 days after the final dose was obtained from the $\mathrm{Na}$ tional Ambulatory Care System (NACRS) database and Canadian Institute for Health Information Discharge Abstract Database (CIHI DAD), respectively. Acute care visits were classified as ED visit only or a hospitalization, defined as having experienced either a direct admission or an ED visit resulting in an admission. Demographic and clinical characteristics of the intervention and control cohorts were summarized using descriptive statistics. Standardized differences were assessed between the patients receiving the intervention and the controls. Negative binomial regression with an offset for time was used to estimate the relationship between event rates and the study intervention, overall and stratified by centre. We undertook a stratified analysis by centre due to the differences in regimen, patient characteristics such as cancer stage and age, baseline rates of acute care utilization, and centre characteristics such as rurality which may affect the way patients would seek and receive medical care but could not be adjusted for due to small sample size. We used clinical expertise and statistical evaluation to select the most important variables for adjustment in regression models.

\section{Results \\ Feasibility}

Between September 2013 and December 2014, 77 patients were accrued at the 2 participating cancer centres; recruitment was slower than anticipated at both sites. At centre 1 , recruitment was initially limited to 2 of the 7 breast clinics and occurred in batches of 10 patients at a time, in order to facilitate the workload of the intervention nurse (who was also a clinical trials nurse). Later, it was expanded to patients from all 7 clinics. At centre 2, initial patient recruitment was carried out by clinic staff and calls were made by a senior clinic nurse with expertise in symptom management. Recruitment was slow due to the lack of a standardized approach to identify eligible patients since this was a new task for the clinic staff and the lack of ethics training by 1 of the physicians in the clinic which made their patients ineligible for recruitment. However, once the local research staff were enlisted to facilitate patient identification, recruitment improved at the centre. Of the 77 patients enrolled, 75 completed the intervention; 1 patient withdrew due to the progression of another illness and 1 died during treatment secondary to sepsis. Demographics and clinical characteristics of the patients are summarized in Table 1.

83.8\% (95\% CI 81.4-86.0\%) of expected calls were delivered per the study schedule. During the course of the intervention, 855 pro-active calls were delivered, with a mean duration of $9 \mathrm{~min}$. The type of symptoms encountered varied by treatment cycle. Symptoms such as nausea, vomiting, and constipation required intervention in early cycles, whereas pain and joint and muscle aches were more prevalent in later cycles, often after the initiation of the taxane-based portion of the regimen. Of the $3131 \mathrm{rec}-$ ommendations made, $56.9 \%$ (95\% CI $55.2-58.7 \%$ ) 
Table 1 Baseline demographic and clinical characteristics of study participants

\begin{tabular}{|c|c|c|c|}
\hline Variable & Centre $1, n=56$ & Centre $2, n=21$ & Total, $n=77$ \\
\hline Age, mean (SD) & $53.8(10.9)$ & $58.7(11.1)$ & $55.1(11.1)$ \\
\hline Married, $n(\%)$ & $38(67.9)$ & $16(76.2)$ & $54(70.1)$ \\
\hline \multicolumn{4}{|l|}{ Highest level of education, $n(\%)$} \\
\hline Less than college/university & $11(19.6)$ & $4(19.0)$ & $15(19.5)$ \\
\hline College/university or higher & $39(69.6)$ & $17(81.0)$ & $66(85.7)$ \\
\hline Prefer not to respond & $6(10.7)$ & 0 & $6(7.8)$ \\
\hline \multicolumn{4}{|l|}{ Combined household income, $n(\%)$} \\
\hline$<\$ 60 k$ & $19(33.9)$ & $5(25.0)$ & $24(31.2)$ \\
\hline$\$ 60-99 k$ & $10(17.9)$ & $5(25.0)$ & $15(19.5)$ \\
\hline$>100 k$ & $11(19.6)$ & $5(25.0)$ & $16(21.1)$ \\
\hline Prefer not to respond & $16(28.6)$ & $5(25.0)$ & $21(27.6)$ \\
\hline \multicolumn{4}{|l|}{ Employment status, $n$ (\%) } \\
\hline Employed (working or on sick leave) & $31(55.4)$ & $10(47.6)$ & $41(53.2)$ \\
\hline Unemployed or retired & $20(35.7)$ & $10(47.6)$ & $30(39.0)$ \\
\hline \multicolumn{4}{|l|}{ Stage, $n(\%)$} \\
\hline Stage I & $6(10.7)$ & $3(15.0)$ & $9(11.8)$ \\
\hline Stage ॥ & $25(44.6)$ & $5(25.0)$ & $30(39.5)$ \\
\hline Stage III & $25(44.6)$ & $12(60.0)$ & $37(48.7)$ \\
\hline \multicolumn{4}{|l|}{ Treatment intent, $n(\%)$} \\
\hline Adjuvant & $42(75.0)$ & $14(70.0)$ & $56(73.7)$ \\
\hline Neoadjuvant & $14(25.0)$ & $6(30.0)$ & $20(26.3)$ \\
\hline \multicolumn{4}{|l|}{ Regimen, $n(\%)$} \\
\hline$A C-P$ & $30(53.6)$ & $15(60.0)$ & $45(58.4)$ \\
\hline FEC-100 & $3(5.4)$ & $5(25.0)$ & $8(10.5)$ \\
\hline FEC-T & $12(21.4)$ & 0 & $12(15.6)$ \\
\hline $\mathrm{TC}$ & $10(17.9)$ & 0 & $10(13.2)$ \\
\hline Other & $1(1.8)$ & $1(5.0)$ & $2(2.6)$ \\
\hline Primary G-CSF prophylaxis, $n(\%)$ & $50(89.2)$ & $9(42.9)$ & $59(76.6)$ \\
\hline Central line, $n(\%)$ & $20(35.7)$ & $5(23.8)$ & $25(32.5)$ \\
\hline \multicolumn{4}{|l|}{ Co-morbidities, $n$ (\%) } \\
\hline Cardiovascular disease & $3(5.4)$ & $2(9.5)$ & $5(6.5)$ \\
\hline Chronic lung disease & $3(5.4)$ & $1(4.8)$ & $4(5.2)$ \\
\hline Diabetes & $4(7.1)$ & $2(9.5)$ & $6(7.8)$ \\
\hline Moderate to severe kidney disease & $1(1.8)$ & $1(4.8)$ & $2(2.6)$ \\
\hline
\end{tabular}

$S D$ standard deviation; $A C-P$ adriamycin, cyclophosphamide, and paclitaxel; FEC-100 5-fluorouracil, epirubicin, and cyclophosphamide; FECT-T 5-fluorouracil, epirubicin, cyclophosphamide, and docetaxel; TC docetaxel and cyclophosphamide; G-CSF granulocyte colony-stimulating factor

were non-pharmacological, $35.1 \% \quad(95 \%$ CI $33.4-$ $36.8 \%$ ) were pharmacological, $7.1 \%$ (95\% CI 6.2-8.0\%) required follow-up at the next clinic visit, and $0.9 \%$ (95\% CI $0.6-1.3 \%)$ were to seek immediate assistance. For most symptoms, there was a roughly equal split in non-pharmacologic and pharmacologic interventions with the exception of fatigue where recommendations were mostly non-pharmacologically focused (Fig. 2).

\section{Acceptability}

Among the 70 patients who completed the end-of-study survey, most reported that their symptoms were well controlled and that they used the self-management guide to manage symptoms during treatment $(85.7 \%$, 95\% CI 75.3-92.9\%; Table 2). The majority of patients liked receiving the calls $(97.1 \%$, 95\% CI 90.1-99.6\%) and would recommend that a similar program be extended to all patients receiving 


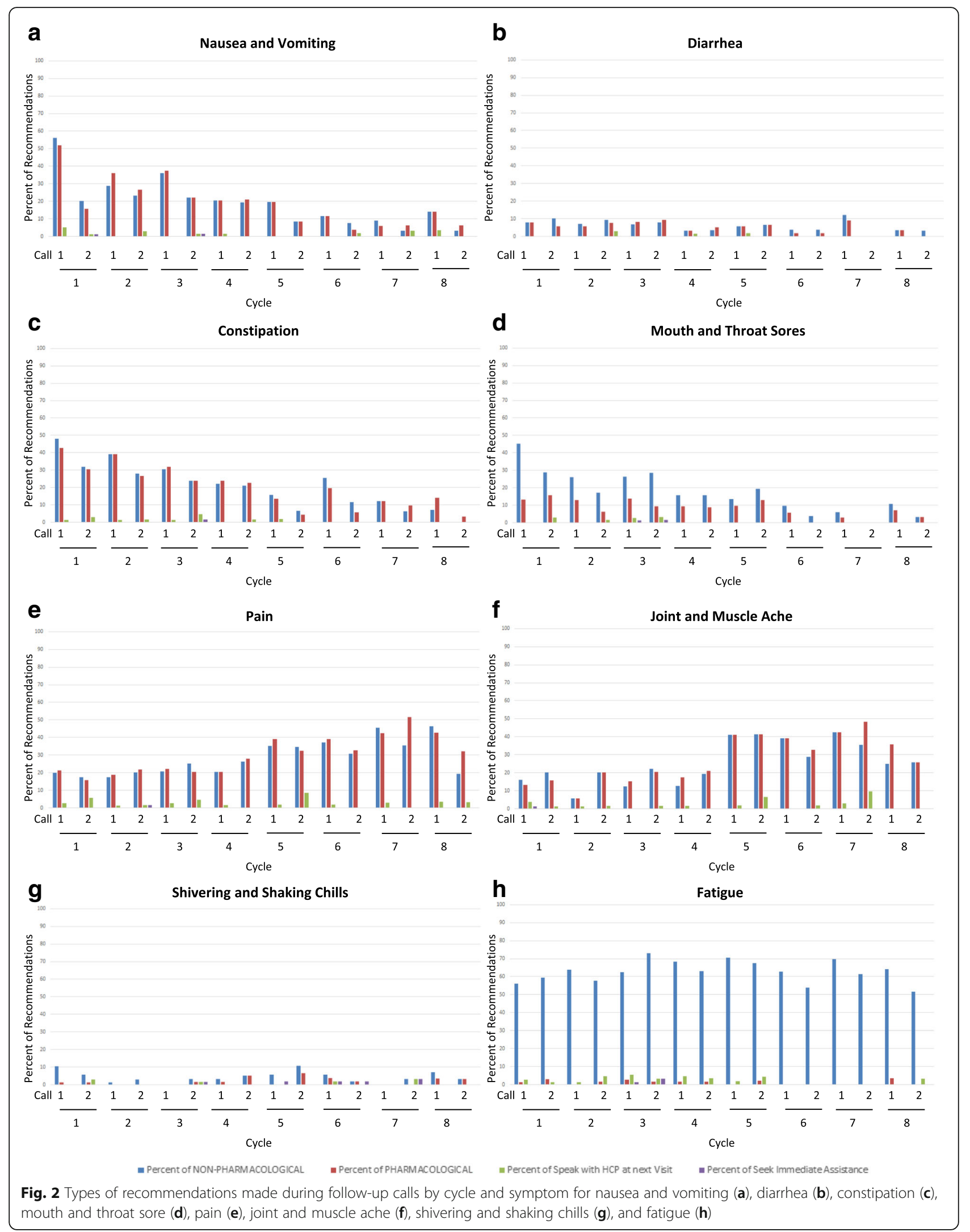


Table 2 End-of-study feedback from participants by study site

\begin{tabular}{|c|c|c|c|c|c|c|c|}
\hline \multirow[t]{2}{*}{ Questions } & \multirow{2}{*}{$\begin{array}{l}\text { Participant } \\
\text { response }\end{array}$} & \multicolumn{2}{|l|}{ Centre 1} & \multicolumn{2}{|l|}{ Centre 2} & \multicolumn{2}{|l|}{ Total } \\
\hline & & $\begin{array}{l}N=49 \\
(\%)\end{array}$ & $95 \% \mathrm{Cl}$ & $\begin{array}{l}N=21 \\
(\%)\end{array}$ & $95 \% \mathrm{Cl}$ & $\begin{array}{l}N=70 \\
(\%)\end{array}$ & $95 \% \mathrm{Cl}$ \\
\hline \multicolumn{8}{|l|}{ NCI PRO-CTCAE tool } \\
\hline $\begin{array}{l}\text { The } \mathrm{NCI} \text { PRO is important because it helps my healthcare team } \\
\text { and research coordinator know what symptom I am having and } \\
\text { how severe they are. }\end{array}$ & $\begin{array}{l}\text { Strongly agree/ } \\
\text { somewhat agree }\end{array}$ & $49(100)$ & $92.8-100$ & $20(95.2)$ & $76.2-99.9$ & $69(98.6)$ & $92.3-100$ \\
\hline $\begin{array}{l}\text { The symptom levels made it easier for me to describe how I am } \\
\text { physically feeling. }\end{array}$ & $\begin{array}{l}\text { Strongly agree/ } \\
\text { somewhat agree }\end{array}$ & $47(95.9)$ & $86.0-99.5$ & $20(95.2)$ & $76.2-99.9$ & $67(95.7)$ & $88.0-99.1$ \\
\hline \multicolumn{8}{|l|}{ Symptom management guide } \\
\hline $\begin{array}{l}\text { During your chemotherapy treatment, did you use the } \\
\text { symptom management guide provided to you? }\end{array}$ & Yes & $45(91.8)$ & $80.4-97.7$ & $15(71.4)$ & $47.8-88.7$ & $60(85.7)$ & $75.3-92.9$ \\
\hline \multirow{4}{*}{$\begin{array}{l}\text { How often did you refer to the symptom management Guide? } \\
\text { (number of times/chemotherapy cycle) }\end{array}$} & Never & $4(8.2)$ & $2.3-19.6$ & $6(28.6)$ & $11.3-52.2$ & $10(14.3)$ & $7.1-24.7$ \\
\hline & $1-3$ & $28(57.1)$ & $42.2-71.1$ & $13(61.9)$ & $38.4-81.9$ & $41(58.6)$ & $46.2-70.2$ \\
\hline & $\begin{array}{l}\text { Greater than } 3 \\
\text { times }\end{array}$ & $12(24.5)$ & $13.3-38.9$ & $2(9.5)$ & $1.2-30.4$ & $14(20.0)$ & $11.4-31.3$ \\
\hline & Missing & $5(10.2)$ & $3.4-22.2$ & 0 & $0-16.1$ & $5(7.1)$ & $2.4-15.9$ \\
\hline $\begin{array}{l}\text { Did you find the symptom management guide helpful in } \\
\text { managing your symptoms related to chemotherapy? }\end{array}$ & $\begin{array}{l}\text { Strongly agree/ } \\
\text { somewhat agree }\end{array}$ & $44(89.7)$ & $77.8-96.6$ & $14(66.7)$ & $43.0-85.4$ & $58(82.9)$ & 72.0-90.8 \\
\hline $\begin{array}{l}\text { Did you feel that the symptom management guide improved } \\
\text { your ability to self-manage your chemotherapy side effects? }\end{array}$ & $\begin{array}{l}\text { Strongly agree/ } \\
\text { somewhat agree }\end{array}$ & $44(89.7)$ & $77.8-96.6$ & $15(71.4)$ & $47.8-88.7$ & $59(84.3)$ & 73.6-91.9 \\
\hline $\begin{array}{l}\text { Did you feel that the symptom management guide helped you } \\
\text { to understand when to seek medical care? }\end{array}$ & $\begin{array}{l}\text { Strongly agree/ } \\
\text { somewhat agree }\end{array}$ & $46(93.9)$ & $83.1-98.7$ & $15(71.4)$ & $47.8-88.7$ & $61(87.1)$ & 77.0-94.0 \\
\hline \multicolumn{8}{|l|}{ Pro-active, telephone-based symptom management calls } \\
\hline Did you like receiving the follow-up phone calls? & $\begin{array}{l}\text { Strongly agree/ } \\
\text { somewhat agree }\end{array}$ & $49(100)$ & $92.8-100$ & $19(90.5)$ & $69.6-98.8$ & $68(97.1)$ & $90.1-99.7$ \\
\hline Did you find the follow-up phone calls to be a burden? & $\begin{array}{l}\text { Strongly agree/ } \\
\text { somewhat agree }\end{array}$ & $2(4.1)$ & $0.5-14.0$ & $2(9.5)$ & $1.2-30.4$ & $4(5.7)$ & $1.6-14.0$ \\
\hline Were the follow-up calls helpful in managing your symptoms? & $\begin{array}{l}\text { Strongly agree/ } \\
\text { somewhat agree }\end{array}$ & $47(95.9)$ & $86.1-99.5$ & $17(81.0)$ & $58.1-94.6$ & $64(91.4)$ & $82.3-96.8$ \\
\hline \multicolumn{8}{|l|}{ Overall } \\
\hline $\begin{array}{l}\text { During treatment, my physical symptoms have been controlled } \\
\text { to a comfortable level (examples of physical symptoms are } \\
\text { nausea, pain, constipation, etc.) }\end{array}$ & $\begin{array}{l}\text { Strongly agree/ } \\
\text { somewhat agree }\end{array}$ & $48(98.0)$ & $89.2-100$ & $20(95.2)$ & $76.2-99.9$ & $68(97.1)$ & $90.1-99.7$ \\
\hline $\begin{array}{l}\text { During treatment, my emotional symptoms have been } \\
\text { controlled to a comfortable level (examples of emotional } \\
\text { symptoms are anxiety, depression, etc.) }\end{array}$ & $\begin{array}{l}\text { Strongly agree/ } \\
\text { somewhat agree }\end{array}$ & $48(98.0)$ & $89.2-100$ & $16(76.2)$ & $52.8-91.8$ & $64(91.4)$ & $82.3-96.8$ \\
\hline \multirow{2}{*}{$\begin{array}{l}\text { Do you feel that participating in this study prevented you from } \\
\text { going to the emergency room as a result of you chemotherapy } \\
\text { side effects? }\end{array}$} & $\begin{array}{l}\text { Strongly agree/ } \\
\text { somewhat agree }\end{array}$ & $35(71.4)$ & $56.7-83.4$ & $12(57.1)$ & $34.0-78.2$ & $47(67.1)$ & $54.9-77.9$ \\
\hline & $\begin{array}{l}\text { Strongly } \\
\text { disagree/ } \\
\text { somewhat } \\
\text { disagree }\end{array}$ & $8(16.3)$ & 7.3-29.7 & $5(23.8)$ & $8.2-47.2$ & 13 (18.6) & $10.3-29.7$ \\
\hline $\begin{array}{l}\text { Would you recommend this study protocol (symptom } \\
\text { assessment, symptom management, and follow-up phone calls) } \\
\text { be adapted to all cancer patients getting chemotherapy? }\end{array}$ & $\begin{array}{l}\text { Strongly agree/ } \\
\text { somewhat agree }\end{array}$ & 47 (95.9) & $86.1-99.5$ & $19(90.5)$ & $69.6-98.8$ & $66(94.3)$ & $86.0-98.4$ \\
\hline
\end{tabular}

Cl confidence interval, NCI PRO CTCAE National Cancer Institute Patient Reported Outcomes Common Terminology Criteria for Adverse Events

chemotherapy $(94.3 \%, 95 \%$ CI $86.0-98.4 \%)$. In the end-of-study interviews, patients reported enjoying the relationship they developed with the nurse delivering the calls and that telephone support helped to normalize their experience and boosted their confidence for self-care by providing just-in-time education and support (Table 3).
Six nurses, two oncologists, and one pharmacist, who were actively involved in delivering the intervention, participated in end-of-study provider interviews. Content analysis of the interviews (summarized in Table 4) indicated that the providers enjoyed participating in the study and felt that the patients benefited from the intervention. Key challenges identified were fitting the 
Table 3 Thematic analysis of end-of-study patient $(n=17)$ interviews

\begin{tabular}{|c|c|c|}
\hline Main themes & Sub-categories & Evidentiary statement \\
\hline \multirow[t]{3}{*}{ Manageability } & $\begin{array}{l}\text { a) Normalized } \\
\text { experience }\end{array}$ & $\begin{array}{l}\text { "The nurse telephone support was } \\
\text { crucial, because if I had a question or } \\
\text { thought it was a weird symptom or } \\
\text { something unusual I could talk to } \\
\text { her'. I think the talking it out with } \\
\text { her and realizing what I thought was } \\
\text { maybe not manageable was } \\
\text { manageable" (1-005). } \\
\text { "You do not know is this how I am } \\
\text { supposed to be feeling? ... Is it } \\
\text { normal to feel this way? So by } \\
\text { having confirmation, by speaking } \\
\text { and reassurance from the study } \\
\text { nurse, it did help" (2-054) }\end{array}$ \\
\hline & $\begin{array}{l}\text { b) Confidence } \\
\text { for self-care }\end{array}$ & $\begin{array}{l}\text { "After talking to her, I was most } \\
\text { confident, I felt so relieved, I feel so } \\
\text { comfortable after talking to her". (2- } \\
\text { 027). } \\
\text { "After the nurse talked to me, I was } \\
\text { so sure of myself that I was going to } \\
\text { be just fine, that I did not have to } \\
\text { worry about anything." (2-033). }\end{array}$ \\
\hline & $\begin{array}{l}\text { c) Expert } \\
\text { personalized } \\
\text { advice }\end{array}$ & $\begin{array}{l}\text { "I live alone. And you, here's } \\
\text { somebody who is concerned about } \\
\text { you, who knows my disease, this } \\
\text { nurse knew my disease. And, when } \\
\text { she gave me any advice it was so } \\
\text { helpful. It was like medicine, taking } \\
\text { some medicine to relax, to relieve } \\
\text { my problem. That's so helpful, really." } \\
\text { (2-027) } \\
\text { "Having somebody that you can call } \\
\text { to say, "Is this normal, I have got this } \\
\text { problem, what should I do, who can } \\
\text { also give you better advice than just, } \\
\text { you know, on the back of a package'. } \\
\text { This is not working for me. How am I } \\
\text { going to make this work? She gave } \\
\text { me really good suggestions. It makes } \\
\text { you know you can deal with it. } \\
\text { Otherwise you feel like you are flying } \\
\text { blind. And that's kind of scary when } \\
\text { you do not feel so good" (2-004). }\end{array}$ \\
\hline
\end{tabular}

Feeling safe a) No need to "She would assure you it was normal, panic so, you know, there is no need to panic over anything". (2-040) "So it feels like you are safe because somebody's asking about you, like somebody from the hospital is calling and saying okay. So I knew... I knew that they were all taking care of me." (2-033)

b) A lifeline, not on your own
"Just overall knowing that, like I said, that she was checking, that I could rely on her to call. If I had any questions or concerns that on a regular basis, I'd be talking to her." (1-005)

"I think knowing that I had a nurse call coming gave me peace of mind." (2-056).
Table 3 Thematic analysis of end-of-study patient $(n=17)$ interviews (Continued)

\begin{tabular}{ll}
\hline Main themes Sub-categories & Evidentiary statement \\
\hline & "I could confidently talk to her about \\
& what really needed to be addressed, \\
& I guess ... I found her almost like a \\
& lifeline to me some days. I just felt \\
& very confident". (1-014) \\
\hline
\end{tabular}

additional responsibilities of the calls within existing responsibilities, documentation processes, and communication of symptom findings with the rest of the clinical team. However, the providers indicated that they thought these challenges could be overcome with appropriate tools and planning. Explicitly defining the process for identifying eligible patients, development of call tracking and documentation tools, training in symptom management for staff delivering the calls, and defining how to communicate outcome of calls were recommended by the provider participants as the main opportunities for improving implementation. There were some challenges specific to the fact that the pilot study involved both regular clinic staff and research personnel; for example, the burden of data collection was a challenge for clinic staff versus adequate experience in symptom management was seen as a potential challenge among some of the research staff.

\section{Acute care use during chemotherapy}

Comparison of study participants and contemporaneous controls using administrative data (Additional file 2: Table S1) revealed that control patients were generally younger, less likely to reside in a low-income neighbourhoods, and more likely to have stage 1 disease than study participants. The types of regimens used and proportion of patients with a history of an ED visit in the year prior to their cancer diagnosis differed by centre. In regression analyses, we adjusted for age, stage, centre, and regimen. In addition, for analyses restricted to centre 2, we also adjusted for history of ED visits a year prior to cancer diagnosis. The overall adjusted incidence rate ratio for ED visits was 0.54 (95\% CI 0.36-0.81) for study participants compared to controls (Table 5). While the incidence of ED visits was lower in study participants compared to controls at both centres in stratified analyses, only the results for centre 2 were statistically significant (adjusted IRR $=0.33$; 95\% CI 0.16-0.67). Hospitalization rates were found to be low in both groups; as such, differences were inconclusive.

\section{Discussion}

Introduction of a standardized, pro-active, telephone-based toxicity management during chemotherapy for early stage breast cancer was feasible, well received by both patients 
Table 4 Thematic analysis of end-of-study provider interviews $(n=9)$

\begin{tabular}{|c|c|c|}
\hline Main themes & Sub-categories & Specific comments \\
\hline \multirow[t]{3}{*}{ What worked well } & a) Patients liked receiving calls & $\begin{array}{l}\text { - Overall the intervention was well received by patients who appreciated the personal } \\
\text { touch the intervention added to their care. } \\
\text { - Reassurance provided to patients regarding their treatment experience reduced } \\
\text { anxiety. } \\
\text { - Patients liked consistent individual performing the calls. }\end{array}$ \\
\hline & $\begin{array}{l}\text { b) Providers liked delivering } \\
\text { the intervention }\end{array}$ & $\begin{array}{l}\text { - Providers enjoyed their involvement. } \\
\text { - Orientation provided to staff prior to their involvement }\end{array}$ \\
\hline & c) Importance of planning & $\begin{array}{l}\text { - Screening breast clinic patient lists to identify patients eligible for the study. } \\
\text { - Determining a scheduled time to make the intervention calls to prevent missed calls. } \\
\text { - The use of a thorough and practical tool to provide structure to the telephone calls. }\end{array}$ \\
\hline \multirow[t]{2}{*}{ What did not work } & $\begin{array}{l}\text { a) Fitting the intervention into } \\
\text { existing work flow }\end{array}$ & $\begin{array}{l}\text { - Providers struggled to fill calls into their existing work schedule. } \\
\text { - Burden of large amounts of data collection and length of form to be completed } \\
\text { during calls. } \\
\text { - Communication between team members and incorporation of NCI PRO-CTCAE into } \\
\text { clinic appointments. } \\
\text { - Inconsistent staff performing intervention calls. } \\
\text { - Patients' confusion regarding who to call if issues arose between calls. }\end{array}$ \\
\hline & $\begin{array}{l}\text { b) Ensuring appropriate } \\
\text { experience }\end{array}$ & $\begin{array}{l}\text { - Clinical trial staff may not have sufficient symptom management experience compared } \\
\text { with nurses working in the chemotherapy clinic. }\end{array}$ \\
\hline \multirow[t]{4}{*}{$\begin{array}{l}\text { Recommendations for } \\
\text { improvement }\end{array}$} & a) Calls & $\begin{array}{l}\text { - Develop a tracking tool for the telephone calls. } \\
\text { - Timing of calls: first call for cycle one should be early. After first cycle, one call at days } \\
5-8 \text { may be sufficient. } \\
\text { - Limit number of providers making follow-up calls. } \\
\text { - Track and manage other common symptoms during calls (e.g., insomnia, anxiety, and } \\
\text { depression). }\end{array}$ \\
\hline & b) Staff training & - Further training on symptom management and organization of workload. \\
\hline & $\begin{array}{l}\text { c) Communication within } \\
\text { circle of care }\end{array}$ & $\begin{array}{l}\text { - Develop process to ensure oncologists and staff are aware of symptom information } \\
\text { reported on NCI PRO-CTCAE. } \\
\text { - Develop documentation process to ensure clear communication between team } \\
\text { members. }\end{array}$ \\
\hline & d) Other & $\begin{array}{l}\text { - Reduce amount of data collection. } \\
\text { - Improve patient symptom management guide-make it more illustrative. }\end{array}$ \\
\hline
\end{tabular}

and providers, and demonstrated promising preliminary results on ED utilization as compared to contemporaneous controls identified from the administrative data. Some issues related to recruitment were encountered, which were related to the availability of local resources to deliver the intervention; these can likely be overcome with changes to the implementation process, in particular, appropriate team planning and simplification of the data collection processes.

The intervention was well received by patients who, in both end-of-study surveys and interviews, indicated that they liked the support that the calls provided and especially enjoyed the relationship they developed with the nurses making the calls. The patients indicated that having real-time support to normalize the experience, and help them navigate symptoms, boosted their confidence for self-care and decreased anxiety. Nurses play a key role in supporting cancer patients throughout their illness, including beyond visits to the cancer clinic [22], but how to deliver effective remote support to patients during treatment is an area of active research. Similar to previous studies, our findings suggest that pro-active, nurse-led telephone management is a promising approach for delivering remote support between clinic visits. Whether other healthcare providers, such as oncology pharmacists [23] or clerical staff [24], could be involved in telephone support remains to be explored. While the study was well received by providers, a number of practical implementation challenges were identified that have not been addressed in previous studies, which have focused on efficacy as opposed to effectiveness of telephone-based toxicity management support.

The greatest challenges we encountered were related to identifying eligible patients, incorporating the calls into existing work responsibilities, and determining the best approach to communicate within the circle of care since the intervention nurses were often different than the usual care team. Our findings suggest that embedding pro-active symptom management into routine care requires a fundamental transformation of the "whole system"; simply adding greater expectations to existing practice systems is unlikely to be successful [25]. In a series of two randomized trials by Mooney et al. in ambulatory patients receiving chemotherapy [7, 26], the addition of a dedicated nurse to respond to symptom 
Table 5 Crude and adjusted emergency department (ED) visits and hospitalization (H) incidence rates in study participants and contemporaneous controls by centre

\begin{tabular}{|c|c|c|c|c|c|c|c|c|c|c|}
\hline & \multirow{2}{*}{$\begin{array}{l}\text { Number of } \\
\text { patients }\end{array}$} & \multirow{2}{*}{$\begin{array}{l}\text { Total } \\
\text { number of } \\
\text { person- } \\
\text { months }\end{array}$} & \multicolumn{4}{|c|}{ Emergency department visits } & \multicolumn{4}{|c|}{ Hospitalizations } \\
\hline & & & $\begin{array}{l}\text { Total ED } \\
\text { visits }\end{array}$ & $\begin{array}{l}\text { IR for ED } \\
\text { visits per } \\
\text { month }\end{array}$ & $\begin{array}{l}\text { Crude IRR } \\
(95 \% \mathrm{Cl})\end{array}$ & $\begin{array}{l}\text { Adjusted IRR } \\
(95 \% \mathrm{Cl})\end{array}$ & $\begin{array}{l}\text { Total } \mathrm{H} \\
\text { visits }\end{array}$ & $\begin{array}{l}\text { IR for } \mathrm{H} \\
\text { visits per } \\
\text { month }\end{array}$ & $\begin{array}{l}\text { Crude IRR } \\
(95 \% \mathrm{Cl})\end{array}$ & $\begin{array}{l}\text { Adjusted IRR } \\
(95 \% \mathrm{Cl})\end{array}$ \\
\hline \multicolumn{11}{|c|}{ Both centres } \\
\hline Control & 215 & 860.3 & 257 & 0.30 & 1.00 (ref) & 1.00 (ref) & 59 & 0.07 & 1.00 (ref) & 1.00 (ref) \\
\hline AToM & 77 & 338.7 & 50 & 0.15 & $0.48(0.32,0.73)$ & $0.54(0.36,0.81)$ & 24 & 0.07 & $1.05(0.60,1.85)$ & $1.02(0.59,1.77)$ \\
\hline \multicolumn{11}{|l|}{ Centre 1} \\
\hline Control & 145 & 592.5 & 114 & 0.19 & 1.00 (ref) & 1.00 (ref) & 31 & 0.05 & 1.00 (ref) & 1.00 (ref) \\
\hline AToM & 56 & 233.4 & 32 & 0.14 & $0.72(0.46,1.11)$ & $0.78(0.51,1.21)$ & 11 & 0.05 & $0.90(0.45,1.80)$ & $0.96(0.48,1.95)$ \\
\hline \multicolumn{11}{|l|}{ Centre 2} \\
\hline Control & 70 & 267.8 & 143 & 0.53 & 1.00 (ref) & 1.00 (ref) & 28 & 0.10 & 1.00 (ref) & 1.00 (ref) \\
\hline AToM & 21 & 105.3 & 18 & 0.17 & $0.29(0.14,0.62)$ & $0.33(0.16,0.67)$ & 13 & 0.12 & $1.27(0.50,3.19)$ & $1.53(0.65,3.59)$ \\
\hline
\end{tabular}

$E D$ emergency department visit, $H$ hospitalization, $I R$ incidence rate, $I R R$ incidence rate ratio, $C l$ confidence interval

${ }^{a}$ Regression model controlled for age, cancer stage, initial chemotherapy regimen, and centre (where applicable)

${ }^{b}$ Regression model controlled for age, cancer stage, initial chemotherapy regimen, history of ED use a year prior to diagnosis, and centre (where applicable)

alerts was associated with improved symptom control, compared to relying on physicians and nurses to respond to the alerts as an add-on to their usual workload. This suggests that either creating a dedicated nursing role or ensuring protected time within an existing role is necessary for successful implementation of remote support programs. Patient identification via electronic health records (EHRs), as well as integrating call outcomes within EHRs, is an area for future study.

The incidence of ED visits during treatment in the patients that participated in the pilot was lower than that in the contemporaneous controls, although the magnitude of the effect varied by centre. While selection bias could explain this finding, telephone-based case management has been shown to decrease re-admissions in chronic diseases, such as heart failure $[4,5]$, and a recent single centre study of remote symptom management during chemotherapy for patients with advanced cancer also reported lower ED rates and hospitalizations in patients randomized to the intervention [13]. Furthermore, fewer acute care visits have been reported from early evaluations of the oncology patient-centred medical home whose core principles include enhanced remote support for patients receiving chemotherapy [22, 26]. We postulate that the most likely mechanism behind the lower rate of ED utilization in the setting of outpatient chemotherapy delivery is early symptom management, although our findings from patient interviews suggest that a component of benefit may be from decreasing anxiety and normalizing the experience of chemotherapy for patients with just-in-time support and standardized education.

Our study should be interpreted in the context of its limitations. We included two different centres to improve the generalizability of the findings, but the number of participating sites and sample size were limited. Furthermore, since not all patients treated at each of the centres during the intervention period were enrolled, potential for selection bias exists. While the intervention details and supporting tools were created centrally by the project steering committee, the centres were given flexibility in how they wanted to implement the intervention and data collection, and some implementation outcomes such as a recruitment rate were not reliably captured. This highlights the importance of conducting formal pilot studies prior to large-scale implementation trials. Involvement of research personnel facilitated patient identification and data collection, but involvement of clinical personnel is essential for sustainability and spread beyond the research setting which is the cornerstone of implementation science. Figuring out the optimal balance between research and clinical personnel in these types of studies requires additional work. Finally, due to the resource limitations, symptom management calls were not recorded or analysed for content; the quality of the calls could have varied by provider. Although our findings suggest that pro-active symptom management may help to optimize care in ambulatory cancer population, larger scale evaluations are needed to determine impact and sustainability. Selecting patients at higher risk of toxicity or focusing the intervention on high-risk periods, such as early in the chemotherapy course or when there is a change in drug, may help to optimize resource use and facilitate scalability of the intervention $[27,28]$; however, a validated prediction model to identify high-risk patients does not currently exist [29]. Further analysis using administrative data and retrospective chart review could help to 
identify high-risk patients and high-risk periods for intervention.

\section{Conclusions}

In summary, our study suggests that pro-active, telephone-based toxicity management during chemotherapy in routine care is feasible, perceived as valuable by patients and providers and may have a positive impact on acute care utilization. Larger-scale evaluations of the impact of this approach on acute care utilization and patient-reported outcomes are warranted, but attention to implementation issues needs to be considered prior to initiation. We are currently conducting a 20-centre cluster-randomized trial of this intervention (NCT02485678).

\section{Additional files}

Additional file 1: Figure S1. Selection of contemporaneous controls in administrative data. (PDF $30 \mathrm{~kb}$ )

Additional file 2: Table S1. Baseline demographic and clinical characteristics of selected controls and study participants from administrative data, by centre. (DOCX $19 \mathrm{~kb}$ )

\section{Acknowledgements}

We would like to thank the pharmacy, nursing and research staff at Sunnybrook Regional Health Sciences Centre and Thunder Bay Regional Health Sciences Centre. We would like to acknowledge Hilary Connor, a nursing student from the Faculty of Nursing at the University of Toronto, for her assistance in coding qualitative data obtained through the patient interviews. We would like to thank all of the patients who participated in this trial.

\section{Funding}

This pilot study was funded by the Ontario Ministry of Health and Long Term Care through Cancer Care Ontario's Regional Systemic Treatment Program.

\section{Availability of data and materials}

The data that support the findings of this study are available from Cancer Care Ontario and Canadian Institute for Health Information $(\mathrm{ClHI})$ but restrictions apply to the availability of these data, which were used under license for the current study, and so are not publicly available. Data are however available from the authors upon reasonable request and with permission of Cancer Care Ontario and $\mathrm{ClHI}$.

\section{Authors' contributions}

MKK, SG, NBL, DH, CLA, KKWC, VK, SM, MN, MaP, and ER conceived/designed the study. $\mathrm{CM}, \mathrm{HH}, \mathrm{SG}, \mathrm{NBL}, \mathrm{DH}, \mathrm{MaP}$, and DKK conducted the data collection. MKK, CM, HH, ME, MeP, and DKK conducted the data analysis. All authors drafted, reviewed, and approved the final manuscript.

\section{Ethics approval and consent to participate}

Approval from the institutional research ethics boards at both participating centres was received prior to initiating the study. Patients provided individual, written consent to participate in the study. In addition, patients provided consent to link their study records to provincial administrative healthcare data holdings to evaluate the impact of the intervention on $\mathrm{ED}+\mathrm{H}$.

\section{Consent for publication}

Aspects of this work have been presented at the American Society of Clinical Oncology Quality Care Symposium, Phoenix, AZ (February 2016); the Applied Research in Cancer Control Conference, Toronto, Ontario (May 2016); and the Multinational Association of Supportive Care in Cancer, Adelaide, Australia (June 2016).

\section{Competing interests}

Authors Cassandra MacKay, Heekyung Han, Maria Eberg, and Erin Redwood are or were employees of Cancer Care Ontario, a not-for-profit agency of the Government of Ontario. All other authors declare that they have no competing interests.

\section{Publisher's Note}

Springer Nature remains neutral with regard to jurisdictional claims in published maps and institutional affiliations.

\section{Author details}

${ }^{1}$ Cancer Care Ontario, Toronto, ON, Canada. ${ }^{2}$ University Health Network, Toronto, ON, Canada. ${ }^{3}$ Sunnybrook Regional Health Sciences Centre, Toronto, ON, Canada. ${ }^{4}$ Thunder Bay Regional Health Sciences Centre, Thunder Bay, ON, Canada. ${ }^{5}$ Canadian Centre for Applied Research in Cancer Control, Toronto, ON, Canada. ${ }^{6}$ National Cancer Institute, Bethesda, MD, USA.

${ }^{7}$ University of Toronto, Toronto, ON, Canada.

Received: 31 August 2018 Accepted: 18 January 2019

Published online: 08 March 2019

\section{References}

1. Prince RM, Atenafu EG, Krzyzanowska MK. Hospitalizations during systemic therapy for metastatic lung cancer: a systematic review of real world vs clinical trial outcomes. JAMA Oncol. 2015:1:1333-9.

2. Prince RM, Powis M, Atenafu EG, Krzyzanowska MK. Hospitalizations and emergency department visits in cancer patients receiving systemic therapy: systematic review and meta-analysis. Eur J Cancer Care. 2019;28:e12909.

3. Galdas P, Darwin Z, Kidd L, Blickem C, McPherson K, Hunt K, Bower P, Gilbody S, Richardson G. The accessibility and acceptability of selfmanagement support interventions for men with long term conditions: a systematic review and meta-synthesis of qualitative studies. BMC Public Health. 2014:14:1230.

4. Andersen RM. Revisiting the behavioral model and access to medical care: does it matter? J Health Soc Behav. 1995;36:1-10.

5. Riegel B, Carlson B, Kopp Z, LePetri B, Glaser D, Unger A. Effect of a standardized nurse case-management telephone intervention on resource use in patients with chronic heart failure. Arch Intern Med. 2002;162:705-12.

6. Given CW, Sikorskii A, Tamkus D, Given B, You M, McCorkle R, Champion V, Decker D. Managing symptoms among patients with breast cancer during chemotherapy: results of a two-arm behavioral trial. J Clin Oncol. 2008;26:5855-62.

7. Mooney K, Beck SL, Wong B, Dunson WA, Wujcik D. An IT-integrated, computer-based telephone system for monitoring patient-reported symptoms: result of two trials. J Clin Oncol. 2013;30(suppl 34):abst 2

8. Kearney N, Miller M, Maguire R, Dolan S, MacDonald R, McLeod J, Maher L, Sinclair L, Norrie J, Wengström Y. WISECARE+: results of a European study of a nursing intervention for the management of chemotherapy-related symptoms. Eur J Oncol Nurs. 2008;12:443-8. https://doi.org/10.1016/j.ejon.2008.07.005.

9. Kearney N, McCann L, Norrie J. Evaluation of a mobile phone-based, advanced symptom management system (ASyMS) in the management of chemotherapy-related toxicity. Support Care Cancer. 2009;17:437-44. https://doi.org/10.1007/s00520-008-0515-0.

10. Coriat R, Boudou-Rouquette P, Durand JP, Forgeot d'Arc P, Martin I, Mir O, Ropert S, Alexandre J, Goldwasser F. Cost effectiveness of integrated medicine in patients with cancer receiving anticancer chemotherapy. J Oncol Pract. 2012;8:205-10. https://doi.org/10.1200/JOP.2011.000447.

11. Kurtz ME, Kurtz JC, Given CW, Given B. Effects of a symptom control intervention on utilization of health care services among cancer patients. Med Sci Monit. 2006;12:CR319-24.

12. Basch $E$, Deal AM, Kris MG, Scher HI, Hudis CA, Sabbatini P, Rogak L, Bennett AV, Dueck AC, Atkinson TM, Chou JF, Dulko D, Sit L, Barz A, Novotny P, Fruscione M, Sloan JA, Schrag D. Symptom monitoring with patientreported outcomes during routine cancer treatment: a randomized controlled trial. J Clin Oncol. 2016;34:557-65.

13. Basch E, Deal AM, Dueck AC, Scher HI, Kris MG, Hudis C, Schrag D. Overall survival results of a trial assessing patient-reported outcomes for symptom monitoring during routine cancer treatment. JAMA. 2017;318: 197-8. https://doi.org/10.1001/jama.2017.7156.

14. Hassett MJ, O'Malley AJ, Pakes JR, Newhouse JP, Earle CC. Frequency and cost of chemotherapy-related serious adverse effects in a population sample of women with breast cancer. J Natl Cancer Inst. 2006;98:1108-17.

15. Enright K, Grunfeld E, Yun L, Moineddin R, Ghannam M, Dent S, Eisen A, Trudeau M, Kaizer L, Earle C, Krzyzanowska MK. Population-based assessment of emergency room visits and hospitalizations among women 
receiving adjuvant chemotherapy for early breast cancer. J Oncol Pract. 2015;11:126-32. https://doi.org/10.1200/JOP.2014.001073.

16. Barcenas CH, Niu J, Zhang N, Zhang Y, Buchholz TA, Elting LS, Hortobagyi GN, Smith BD, Giordano SH. Risk of hospitalization according to chemotherapy regimen in early-stage breast cancer. J Clin Oncol. 2014;32:2010-7.

17. Basch E, Reeve BB, Mitchell SA, Clauser SB, Minasian LM, Dueck AC, Mendoza TR, Hay J, Atkinson TM, Abernethy AP, Bruner DW, Cleeland CS, Sloan JA, Chilukuri R, Baumgartner P, Denicoff A, St Germain D, O'Mara AM, Chen A, Kelaghan J, Bennett AV, Sit L, Rogak L, Barz A, Paul DB, Schrag D. Development of the National Cancer Institute's patient-reported outcomes version of the common terminology criteria for adverse events (PRO(TCAE). J Natl Cancer Inst. 2014;106:dju244.

18. Dueck AC, Mendoza TR, Mitchell SA, Reeve BB, Castro KM, Rogak $L$, Atkinson TM, Bennett AV, Denicoff AM, O'Mara AM, Li Y, Clauser SB, Bryant DM, Bearden JD 3rd, Gillis TA, Harness JK, Siegel RD, Paul DB, Cleeland CS, Schrag D, Sloan JA, Abernethy AP, Bruner DW, Minasian LM, Basch E. Validity and reliability of the US National Cancer Institute's Patient-Reported Outcomes version of the Common Terminology Criteria for Adverse Events (PRO-CTCAE). JAMA Oncol. 2015;1:1051-9.

19. Lancaster GA, Dodd S, Williamson PR. Design and analysis of pilot studies: recommendations for good practice. J Eval Clin Pract. 2004;10:307-12.

20. Julios SA. Sample size of 12 per group rule of thumb for a pilot study. Pharmaceutl Statist. 2005;4:287-91.

21. Elo A, Kyngas H. The qualitative content analysis process. J of Adv Nurs. 2007:62:107-15.

22. Stacey D, Macartney G, Carley M, Harrison MB. Development and evaluation of evidence-informed clinical nursing protocols for remote assessment, triage and support of cancer treatment-induced symptoms. Nurs Res Pract. 2013;2013:171872.

23. Ignoffo R, Knapp K, Barnett M, Barbour SY, D'Amato S, lacovelli L, Knudsen J, Koontz SE, Mancini R, McBride A, McCauley D, Medina P, O'Bryant CL, Scarpace S, Stricker S, Trovato JA. Board-certified oncology pharmacists: their potential contribution to reducing a shortfall in oncology patient visits. J Oncol Pract. 2016;12:e359-68. https://doi.org/10.1200/JOP.2015.008490.

24. Waters TM, Webster JA, Stevens LA, Li T, Kaplan CM, Graetz I, McAneny BL. Community oncology medical homes: physician-driven change to improve patient care and reduce costs. J Oncol Pract. 2015;11:462-7.

25. Ory MG, Ahn S, Jiang L, Smith ML, Ritter PL, Whitelaw N, Lorig K. Successes of a national study of the chronic disease self-management program: meeting the triple aim of health care reform. Med Care. 2013;51:992-8.

26. Mooney KH, Beck SL, Friedman RH, Farzanfar R, Wong B. Automated monitoring of symptoms during ambulatory chemotherapy and oncology providers' use of the information: a randomized controlled clinical trial. Support Care Cancer. 2014; 22:2343-50. https://doi.org/10.1007/s00520-014-2216-1.

27. Lyman GH, Kuderer NM, Crawford J, Wolff DA, Culakova E, Poniewierski MS, Dale DC. Predicting individual risk of neutropenic complications in patients receiving cancer chemotherapy. Cancer. 2011;117:1917-27.

28. Hosmer W, Malin J, Wong M. Development and validation of a prediction model for the risk of developing febrile neutropenia in the first cycle of chemotherapy among elderly patients with breast, lung, colorectal, and prostate cancer. Support Care Cancer. 2011;19:333-41. https://doi.org/10.1007/s00520-010-0821-1.

29. Ganz P. Delivering patient-centered care in the setting of advanced cancer: what does a clinical risk-prediction model have to do with it? JAMA Oncol. 2015;1:430-2.

Ready to submit your research? Choose BMC and benefit from:

- fast, convenient online submission

- thorough peer review by experienced researchers in your field

- rapid publication on acceptance

- support for research data, including large and complex data types

- gold Open Access which fosters wider collaboration and increased citations

- maximum visibility for your research: over $100 \mathrm{M}$ website views per year

At BMC, research is always in progress.

Learn more biomedcentral.com/submissions 